Jurnal Care Vol .6, No.1,Tahun 2018

\title{
Pengaruh Pendidikan Kesehatan Terhadap Sikap dan Perilaku Personal hygiene Gigi dan Mulut Anak Usia Dekolah di SD Negeri Payung
}

\author{
Sulastri \\ Akademi Keperawatan Muhammadiyah Kendal \\ e-mail : sulastri.jihan@yahoo.co.id
}

\begin{abstract}
Personal hygiene is a basic human need that must always be fulfilled, ncluded in specific primary precautions. Personal bygiene is important because good Personal bygiene will prevent a person from illness. Poor Personal bygiene will make it easier for the body to develop various diseases such as skin diseases, infectious diseases, dental and oral diseases and gastrointestinal diseases. In general, this study aims to determine the bealth educator on behavior and behavior in maintaining Personal hygiene tooth and mouth in school-age children in SD Negeri Payung. This research is an experimental research with pre test design - post test one group design and research instrument in the form of questionnaire. Respondents who are the subject of the research are all the students of grade 3 and 4 SD Negeri Payung which amounted to 36 people. Sampling technique total sampling. The results were obtained before the health education of Personal hygiene of teeth and mouth of the majority of respondents behave badly 25 (69,4\%) while the good behavior was 11 (30,6\%). After the bealth education of Personal hygiene of tooth and mouth the majority of respondents well behaved 30 (83,3\%) while the behavior was not good equal to $6(16,7 \%)$. Suggestions are expected to maintain Personal hygiene tooth and mouth properly and correctly and do not forget the personal way of tooth and mouth hygiene so free from disease.
\end{abstract}

Keywords: Health Education; personal hygiene; teeth and mouth

\begin{abstract}
ABSTRAK
Personal bygiene merupakan kebutuhan dasar manusia yang harus senantiasa terpenuhi., termasuk kedalam tindakan pencegahan primer yang spesifik. Personal hygiene menjadi penting karena Personal hygiene yang baik akan mencegah seseorang dari penyakit. Personal hygiene yang tidak baik akan mempermudah tubuh terserang berbagai penyakit seperti penyakit kulit, penyakit infeksi, penyakit gigi dan mulut dan penyakit saluran cerna. Penelitian ini bertujuan untuk mengetahui pengaruh pendidikan kesehatan terhadap sikap dan perilaku dalam memelihara Personal hygiene gigi dan mulut pada anak usia sekolah di SD Negeri Payung. Penelitian ini merupakan penelitian eksperimental dengan desain pre test-post test one group design dan instrumen penelitiannya berupa kuesioner. Responden yang menjadi subjek penelitian adalah seluruh seluruh siswa kelas 3 dan 4 SD Negeri Payung yang berjumlah 36 orang. Teknik sampling menggunakan total sampling. Hasil penelitian didapatkan sebelum pendidikan kesehatan Personal hygiene gigi dan mulut mayoritas responden berperilaku tidak baik sebesar $25(69,4 \%)$ sedangkan yang berperilaku baik sebesar 11 (30,6\%). Setelah pendidikan kesehatan Personal hygiene gigi dan mulut mayoritas responden berperilaku baik sebesar $30(83,3 \%)$ sedangkan yang berperilaku tidak baik sebesar 6 (16,7\%). Saran
\end{abstract}


diharapkan dapat memelihara Personal hygiene gigi dan mulut dengan baik dan benar dan tidak melupakan cara Personal hygiene gigi dan mulut sehingga terbebas dari penyakit.

Kata Kunci: Gigi dan mulut; pendidikan kesehatan; personal bygiene

\section{PENDAHULUAN}

Perawatan diri atau kebersihan diri (personal higiene) merupakan perawatan diri sendiri yang dilakukan untuk mempertahankan kesehatan, baik secara fisik maupun psikologis. Pemenuhan perawatan diri di pengaruhi berbagai faktor, diantaranya budaya, nilai, sosial pada individu atau keluarga, pengetahuan terhadap perawatan diri serta persepsi terhadap perawatan diri (Syaifudin, 2012). Personal bygiene merupakan kebutuhan dasar manusia yang harus senantiasa terpenuhi (Hidayat, 2012). Personal hygiene termasuk kedalam tindakan pencegahan primer yang spesifik. Personal bygiene menjadi penting karena personal bygiene yang baik akan mencegah seseorang dari penyakit. Personal bygiene yang tidak baik akan mempermudah tubuh terserang berbagai penyakit seperti penyakit kulit, penyakit infeksi, penyakit gigi dan mulut dan penyakit saluran cerna.

Tujuan umum perawatan diri adalah untuk mempertahankan perawatan diri, baik secara sendiri maupun dengan menggunakan bantuan, dapat melatih hidup sehat / bersih dengan cara memperbaiki gambaran atau persepsi terhadap kesehatan dan kebersihan, serta menciptakan penampilan yang sesuai dengan kebutuhan kesehatan membuat rasa nyaman dan relaksasi dapat dilakukan untuk menghilangkan kelelahan serta mencegah infeksi, mencegah gangguan sirkulasi darah, dan mempertahankan integritas pada jaringan (Potter P, 2010).

Organisasi Kesehatan Dunia (WHO) mendefinisikan kesehatan tidak sebatas bebas dari penyakit. Lebih dari itu, individu yang bersangkutan harus sejahtera secara fisik dan mental serta mampu mewujudkan kehidupan sosial dan ekonomi (Jaidin A, 2011). Kesehatan merupakan asset yang paling berharga bagi kesejahteraan hidup manusia, oleh karenanya harus selalu di jaga dan dirawat. Mengingat biaya pengobatan yang semakin hari semakin tidak terjangkau, maka menjaga kesehatan merupakan suatu keharusan, diantaranya adalah dengan cara memelihara dan menjaga kebersihan gigi dan mulut. 
Gigi dan mulut adalah bagian penting yang harus dipertahankan kebersihannya, sebab melalui organ ini berbagai kuman dapat masuk dan berkembang biak sehingga bisa menyebabkan berbagai macam penyakit diantaranya penyakit gigi dan mulut (Masnindar S, 2012). Perilaku sehat bagi siswa SD merupakan modal menuju kearah hidup sehat perlu terus dibina dan anak adalah generasi penerus bangsa. Belum optimalnya kesehatan termasuk kesehatan gigi dan mulut siswa SD di sebabkan oleh karena minimalnya pengetahuan tentang kesehatan gigi dan mulut dan oleh karena perilakunya belum mewujudkan perilaku sehat (Masnindar S, 2012).

Upaya pemeliharaan kesehatan gigi dan mulut sebaiknya dilakukan sejak usia dini. Usia sekolah dasar merupakan saat yang ideal untuk melatih kemampuan motorik seorang anak, termasuk diantaranya menyikat gigi. Upaya peninggkatan derajat kesehatan menjadi tanggung jawab individu, masyarakat dan pemerintah. Penelitian yang dilakukan oleh Ariani (2011) tentang pengaruh perubahan tingkat pengetahuan kesehatan gigi dan mulut pada pelajar usia 7-8 tahun di dua sekolah dasar Kecamatan Mandiangin Koto Selayan Kota Bukittinggi melalui permainan edukasi kedokteran gigi didapatkan hasil rata-rata selisih tingkat pengetahuan pada kelompok eksperimen 13,32 dan pada kelompok kontrol 4,44\%.

Penelitian yang sama dilakukan oleh Sumirat (2013) tentang pengaruh penyuluhan terhadap tingkat pengetahuan siswa kelas V SD tentang perawatan gigi dengan hasil sebelum penyuluhan tingkat pengetahuan cukup 18 (60\%), setelah diberikan penyuluhan pengetahuan bertambah menjadi 21 (70\%). Penelitian yang sama dilakukan oleh Gunawan (2014) didapatkan hasil rerata indek plak gigi sebelum penyuluhan cara menyikat gigi sebanyak 1,53 dan setelah diberikan penyuluhan cara menyikat gigi rerata berkurang menjadi 0,43. Penelitian yang sejenis dilakukan oleh Kurniasari (2011) pengaruh penyuluhan kesehatan gigi dan mulut terhadap kebersihan gigi dan mulut ddiapatkan hasil kriteria buruk sebanyak $14(43,8 \%)$ dan sebagian kecil 4 (15,6\%), kriteria baik sebanyak $17(53,1 \%)$ dan $4(12,5 \%)$ dengan tingkat buruk.

Pembenahan perilaku tidak sehat sebaiknya melalui pendidikan kesehatan yang benar secara konseptual. Mekanisme terjadinya di awali dari perilaku kognitif menuju ke perilaku afektif kemudian 
berlanjut ke perilaku psikomotorik (Maryono, 2012). Informasi mengenai kesehatan gigi dan mulut yang diperoleh siswa-siswa di sekolah belum maksimal. Informasi yang diperoleh dari mata pelajaran, hanya sebatas pengetahuan mengenai pertumbuhan gigi dan masingmasing fungsinya. Materi yang disampaikan pendidik tidak membahas pentingnya memelihara kesehatan gigi dan mulut.

Sekolah adalah perpanjangan tangan keluarga dalam melakukan dasar perilaku untuk kehidupan anak selanjutnya termasuk perilaku kesehatan. Sementara itu populasi anak sekolah di dalam suatu komunitas cukup besar, oleh sebab itu penyuluhan kesehatan di sekolah sangat penting. Komunitas sekolah yang terdiri dari murid, guru, dan karyawan sekolah ditingkat sekolah dasar merupakan sasaran dari promosi kesehatan di sekolah melalui penyuluhan kesehatan. Khususnya bagi siswa usia 9-12 tahun yaitu kelas III dan IV dimana pada masa ini seorang anak memerlukan pengalaman yang nyata untuk dapat menghubungkan apa yang telah mereka pelajari dengan apa yang mereka lihat sehingga fungsi dari penyuluhan kesehatan itu sendiri diarahkan agar anak dapat memupuk tanggung jawab terhadap masyarakat dan diri sendiri. Adanya fenomena seperti ini menjadikan peneliti tertarik untuk mengangkat permasalahan ini sebagai bahan penelitian.

\section{METODE PENELITIAN}

Penelitian kuantitatif, menggunakan eksperimental dengan desain pre test - post test one group design. Jumlah populasi sebanyak 36 anak. Teknik sampling yang digunakan total populasi.Variabel penelitian pendidikan kesehatan terhadap sikap dan perilaku memelihara Personal hygiene gigi dan mulut pada anak usia sekolah. Analisa data menggunakan uji Kolmolgorov Smirnov 2 beda.

\section{HASIL}

Tabel 1. Distribusi frekuensi sikap dalam memelihara Personal hygiene gigi dan mulut, sebelum pendidikan kesehatan

\begin{tabular}{lcc}
\hline $\begin{array}{l}\text { Sebelum } \\
\text { Pendidikan }\end{array}$ & Jumlah & $\%$ \\
kesehatan & & \\
\hline Tidakbaik & 23 & 63,9 \\
Baik & 13 & 36,1 \\
\hline Total & 36 & 100,0 \\
\hline
\end{tabular}

Tabel 1 sebelum pendidikan kesehatan mayoritas responden mempunyai sikap tidak baik sebesar $23(63,9 \%)$ 
Tabel 2 Distribusi frekuensi sikap dalam memelihara Personal hygiene gigi dan mulut, setelah pendidikan kesehatan

\begin{tabular}{|c|c|c|}
\hline $\begin{array}{l}\text { Setelah } \\
\text { Pendidikan } \\
\text { Kesehatan }\end{array}$ & Jumlah & $\%$ \\
\hline Tidakbaik & 11 & 30,6 \\
\hline Baik & 25 & 69,4 \\
\hline Total & 36 & 100,0 \\
\hline
\end{tabular}

Berdasarkan Tabel 2 setelah pendidikan kesehatan mayoritas responden mempunyai sikap baik sebesar $25(69,4 \%)$

Tabel 3. Distribusi frekuensi perilaku dalam memelihara Personal hygiene gigi dan mulut, sebelum pendidikan kesehatan

\begin{tabular}{lcc}
\hline $\begin{array}{l}\text { Sebelum } \\
\text { penkes }\end{array}$ & Jumlah & $\mathbf{\%}$ \\
\hline Tidakbaik & 23 & 63,9 \\
Baik & 13 & 36,1 \\
\hline Total & 36 & 100,0 \\
\hline
\end{tabular}

Berdasarkan Tabel 3 sebelum pendidikan kesehatan mayoritas responden mempunyai sikap tidak baik sebesar $23(63,9 \%)$

Tabel 4. Distribusi frekuensi perilaku dalam memelihara Personal hygiene gigi dan mulut, setelah pendidikan kesehatan

\begin{tabular}{lcc}
\hline $\begin{array}{l}\text { Setelah } \\
\text { penkes }\end{array}$ & Jumlah & $\mathbf{\%}$ \\
\hline Tidakbaik & 11 & 30,6 \\
Baik & 25 & 69,4 \\
\hline Total & 36 & 100,0 \\
\hline
\end{tabular}

Berdasarkan Tabel 4 setelah pendidikan kesehatan mayoritas responden mempunyai sikap baik sebesar 25 (69,4\%)

\section{PEMBAHASAN}

Sebelum pendidikan kesehatan Personal hygiene gigi dan mulut mayoritas responden berperilaku tidak baik sebesar $23(63,9 \%)$ sedangkan yang berperilaku baik sebesar 13 (36,1\%). Pendidikan kesehatan adalah proses yang menjembatani kesenjangan antara informasi kesehatan dan praktek kesehatan, yang memotivasi seseorang untuk memperoleh informasi dan berbuat sesuatu sehingga dapat menjaga dirinya menjadi lebih sehat dengan menghindari kebiasaan yang buruk dan membentuk kebiasaan yang baik untuk kesehatan (Notoatmodjo, 2012)

Perilaku pada hakekatnya adalah suatu aktivitas daripada individu atau manusia itu sendiri, oleh karena itu perilaku mempunyai bentangan yang sangat luas, perilaku manusia dipengaruhi oleh faktor genetik dan lingkungan (Budioro, 2012). Perilaku sebelum dilakukan pendidikan kesehatan pada anak kelas 3 dan 4 SD Negeri payung kurang baik dikarenakan mereka mendapatkan informasi mengenai 
kesehatan gigi dan mulut di sekolah belum maksimal. Informasi yang diperoleh dari mata pelajaran, hanya sebatas pengetahuan mengenai pertumbuhan gigi dan masingmasing fungsinya. Materi yang disampaikan pendidik tidak membahas pentingnya memelihara kesehatan gigi dan mulut.

Dengan kurangnya informasi yang didapatkan sudah tentu mereka berperilaku tidak baik, sehingga sebelum diadakan pendidikan kesehatan personal bygiene gigi dan mulut murid-murid kelas 3 dan 4 SD berperilaku tidak baik. Perilaku yang tidak baik pada siswa kelas 3 dan 4 SD Negeri Payung dipengaruhi oleh fungsi keluarga belum maksimal dalam memberikan informasi personal hygiene gigi dan mulut sebanyak 13 (36,1\%). Ada beberapa faktor yang mempengaruhi perilaku anak kelas 3 dan 4 SD Negeri Payung kurang baik yaitu karena tingkat sosial ekonomi anak kurang, sarana dan prasarana di rumah dan di sekolah kurang mendukung orang tau dan guru tidak pernah mengingatkan anak untuk melakukan personal bygiene gigi dan mulut dengan baik dan benar sebanyak $56(67,9 \%)$.
Kurangnya sumber informasi menyebabkan informasi atau pesan yang diterima anak kelas 3 dan 4 SD Negeri Payung menjadi kurang, padahal perilaku seseorang dapat bertambah menjadi baik dengan informasi- informasi tertentu, dimana informasi dapat diperoleh melalui media massa maupun lingkungan. Bentuk dari informasi dapat berupa lisan maupun tertulis dan pengalaman yang diperoleh dari fakta atau kenyataan dengan melihat dan mendengar. Pengalaman sendiri merupakan sesuatu yang pernah dialami seseorang yang akan merubah perilaku seseorang (Notoatmodjo, 2012). Setelah pendidikan kesehatan personal bygiene gigi dan mulut mayoritas responden berperilaku baik sebesar 25 (69,4\%) sedangkan yang berperilaku tidak baik sebesar $11(30,6 \%)$.

Pendidikan kesehatan adalah proses perubahan pada diri seseorang yang dihubungkan dengan pencapaian tujuan kesehatan individu dan masyarakat. (Budioro, 2012). Tujuan dari pendidikan kesehatan ialah mengubah perilaku anak kelas 3 dan 4 SD Negeri Payung supaya mereka berperilaku hidup sehat, memanfaatkan fasilitas kesehatan yang ada dan melakukan personal bygiene gigi dan mulut dengan benar. Tujuan diadakan 
pendidikan kesehatan yaitu mengubah pemahaman siswa kelas 3 dan 4 SD Negeri Payung di bidang kesehatan yaitu memelihara kesehatan personal bygiene gigi dan mulut sebagai sesuatu yang bernilai dan mandiri dalam mencapai tujuan hidup.

Personal bygiene merupakan kebutuhan dasar manusia yang harus senantiasa terpenuhi (Hidayat, 2012). Personal bygiene termasuk kedalam tindakan pencegahan primer yang spesifik (Masnindar S, 2012). Personal bygiene menjadi penting untuk anak kelas 3 dan 4 SD Negeri Payung karena Personal hygiene yang baik akan mencegah berbagai macam penyakit. Personal hygiene yang tidak baik akan mempermudah tubuh terserang berbagai penyakit seperti penyakit kulit, penyakit infeksi, penyakit gigi dan mulut dan penyakit saluran cerna (Potter P, 2010).

Dalam penelitian ini mayoritas responden berperilaku baik setelah di lakukan pendidikan kesehatan dikarenakan mereka diarahkan agar dapat mengerti cara personal bygiene gigi dan mulut yang baik termasuk mereka menghubungkan apa yang mereka pelajari dengan apa yang mereka lihat.
Dengan diadakannya pendidikan kesehatan maka akan diperoleh informasiinformasi mengenai personal hygiene gigi dan mulut sehingga pengetahuan anak kelas 3 dan 4 SD Negeri Payung bertambah. Selanjutnya dengan pengetahuan itu akan menumbuhkan kesadaran dan akhirnya akan merubah perilaku sesuai dengan pengetahuannya. Hasil dari perubahan akan bersifat langgeng karena didasari oleh rasa kesadaran mereka sendiri (bukan karena paksaan).

Perubahan perilaku dapat di tempuh dengan beberapa cara seperti dengan paksaan, dengan memberi imbalan, dengan membina hubungan baik, dengan menunjukkan contoh-contoh, dengan memberikan kemudahan dan menenamkan kesadaran dan motivasi. Pada penelitian ini perubahan perilaku anak kelas 3 dan 4 SD Negeri Payung perilaku dirubah dengan membina hubungan baik, menunjukkan contohcontoh, menanamkan kesadaran dan memberikan motivasi untuk memelihara personal bygiene gigi dan mulut, sehingga dengan kesadaran yang dimiliki anak kelas 3 dan 4 SD Negeri Payung akan bergerak untuk berperilaku sehat. 
Mengadakan suatu perubahan ada beberapa langkah yaitu tahap awareness, tahap interrest, tahap evaluasi, tahap trial, dan tahap adaption (Hidayat. A, 2012). Pada awalnya peneliti melakukan perubahan perilaku memelihara kesehatan personal hygiene gigi dan mulut yaitu dengan menumbuhkan kesadaran anak kelas 3 dan 4 SD Negeri payung sehingga dengan kesadaran anak kelas 3 dan 4 SD Negeri Payung perilakunya akan berubah, selanjutnya dengan menimbulkan perasaan minat untuk melakukan personal hygiene gigi dan mulut. Setelah menumbuhkan kesadaan dan menimbulkan perasaan minat maka peneliti melakukan evaluasi terhadap perubahan, kemudian melakukan pendidikan kesehatan personal bygiene gigi dan mulut setelah itu baru di lihat hasil dari pendidikan kesehatan personal bygiene gigi dan mulut, dan mengamati keseluran terhadap perubahan yang sudah dilakukan.

Berdasarkan hasil penelitian sebelum dan setelah pemberian pendidikan kesehatan tentang personal hygiene gigi dan mulut maka terjadi peningkatkan perilaku tentang cara personal bygiene gigi dan mulut yang sesuai dengan prosedur yang benar (Notoatmodjo, 2012). Peningkatan perilaku dapat terjadi karena adanya proses belajar pada diri seseorang. Perilaku individu sangat besar pengaruhnya terhadap kesehatan. Perilaku yang positif dalam arti perilaku kesehatan akan menunjang atau mempertinggi derajat kesehatan seseorang (Notoatmodjo, 2012).

Persepsi adalah proses dari diri seseorang dalam memahami lingkungannya yang melibatkan pengorganisasian dan penafsiran sebagai rangsangan dalam penerimaan rangsangan dari suatu pengalaman psikologis. persepsi berperan dalam penerimaan rangsangan, mengaturnya dan menterjemahkan atau menginterprestasikan rangsangan yang sudah teratur untuk mempengaruhi perilaku dan membentuk sikap. Anak kelas 3 dan 4 SD Negeri Payung setelah pendidikan kesehatan personal bygiene gigi dan mulut mempunyai perilaku yang baik karena mereka menerima materi di pelajari dan menerapkan apa yang mereka peroleh yaitu tentang cara Personal hygiene gigi dan mulut.

Di dalam kegiatan belajar terdapat tiga persoalan pokok, yakni persoalan masukan (input), proses, dan keluaran (output). Persoalan masukan pendidikan kesehatan tentang personal bygiene gigi dan 
mulut adalah menyangkut sasaran pendidikan kesehatan yaitu siswa kelas 3 dan 4 SD Negeri Payung. Persoalan proses adalah mekanisme dan interaksi terjadinya perubahan kemampuan dalam memberikan pendidikan kesehatan personal hygiene gigi dan mulut sesuai dengan prosedur yang tepat dan benar. Di dalam proses pemberian pendidikan kesehatan terjadi pengaruh timbal balik antara beberapa unsur yang meliputi penyuluh, sasaran, dan materi yang diberikan, media dan teknik atau metode yang digunakan. Keluaran adalah merupakan hasil dari kegiatan pendidikan kesehatan berupa perilaku dalam pendidikan kesehatan Personal bygiene gigi dan mulut sehingga mereka terbebas dari penyakit gigi dan mulut. Pendidikan kesehatan tentang personal bygiene gigi dan mulut yang diberikan kepada anak kelas 3 dan 4 SD Negeri Payung mempunyai pengaruh terhadap peningkatan perilaku yang lebih baik. Peningkatan perilaku yang terjadi bisa dikarenakan bertambahnya informasi yang dimiliki anak kelas 3 dan 4 SD Negeri Payung.

Perubahan yang terjadi pada siswa kelas 3 dan 4 SD Negeri Payung setelah diberikan pendidikan kesehatan Personal bygiene gigi dan mulut dikarenakan metode yang di gunakan dalam pendidikan kesehatan sesuai dengan kebutuhan siswa kelas 3 dan 4 SD Negeri payung, materi yang di sampaikan dalam pendidikan kesehatan sesuai dengan kebutuhan siswa kelas 3 dan 4 SD Negeri Payung, adanya ketertarikan pada materi yang di berikan pada peneliti dan keterlibatan orang yang berpengaruh di sekolah yaitu bapak dan ibu guru.

Tujuan diberikannya pendidikan kesehatan Personal hygiene gigi dan mulut yaitu supaya siswa kelas 3 dan 4 SD Negeri Payung mempunyai tanggung jawab yang besar terhadap kesehatan, siswa kelas 3 dan 4 SD Negeri Payung dapat memelihara kesehatan Personal hygiene gigi dan mulut untuk mencegah terjadinya penyakit dan melatih kedisiplinan.Sesuai dengan upaya kesehatan keluarga yang tercantum dalam Undang-undang Kesehatan No 23 Tahun 1992 Pasal 17 yaitu tentang kesehatan anak diselenggarakan untuk mewujudkan perkembangan dan pertumbuhan anak dilakukan melalui peningkatan kesehatan anak dalam kandungan, masa bayi, masa balita, usia prasekolah, dan usia sekolah. Pendidikan kesehatan yang diberikan bertujuan membantu anak-anak supaya 
tumbuh menjadi sehat dan terbebas dari penyakit.

\section{KESIMPULAN}

Ada perbedaan yang bermakna sebelum dan sesudah dilakukan pendidikan kesehatan dalam memelihara personal bygiene gigi dan mulut.

\section{REFERENSI}

Budioro.(2012).Pengantar Pendidikan (Penyuluban) Kesehatan Masyarakat, Edisi Revisi, Semarang : UNDIP

Hidayat.(2012). Pengantar Kebut Dasar Manusia:Aplikasi Konsep dan Proses Keperawatan, Jakarta : Salemba Medika

Jaidin,A.(2011). Dasar Keperawatan Profesional, Jakarta : Widya Medika
Maryono, 2012. Mekanisme Perubahan Perilaku SD, From : bttp://wnwadlu.lib.unair.ac.id/go. Diakses pada tanggal 18 Oktober 2012

Masnindar,S.(2012). Gigi Kuning, From : http://blogspot.com. Diakses pada tanggal 18 Oktober 2012

Notoatmodjo.(2012). Prinsip-prinsip Dasar Ilmu Kesehatan Masyarakat, Edisi ke 2, Jakarta : Rineka Cipta

Potter,P.(2010). Fundamental Of Nursing : Conceps,Proces and Practice, Edisi 4, Jakarta : EGC

Syaifudin.(2012). Promosi Kesehatan Untuke Mabasiswa Kebidanan. Edisi 1, Jakarta : CV Trans Info Media. 